\title{
CADASIL presenting as status migrainosus and persisting aura without infarction
}

\author{
Simona Sacco $\cdot$ Maurizia Rasura $\cdot$ Marina Cao $\cdot$ \\ Alessandro Bozzao $\cdot$ Antonio Carolei
}

Received: 6 August 2008/ Accepted: 8 October 2008/Published online: 25 October 2008

(c) Springer-Verlag 2008

\begin{abstract}
Different types of migraine have been reported in $20-40 \%$ of patients with cerebral autosomal dominant arteriopathy with subcortical infarcts and leukoencephalopathy (CADASIL). We describe a novel migrainous manifestation of CADASIL consisting in status migrainosus and persistent aura without infarction. The symptoms resolved after i.v. treatment with lorazepam and mannitol.
\end{abstract}

Keywords CADASIL $\cdot$ Migraine $\cdot$ Aura $\cdot$ Headache $\cdot$ Triptans · International Classification of Headache Disorders

\section{Abbreviations \\ CADASIL Cerebral autosomal dominant arteriopathy with subcortical infarcts and leukoencephalopathy \\ MRI Magnetic resonance imaging \\ ICHD-2 International Classification of Headache Disorders, Second Edition}

\section{Introduction}

Cerebral autosomal dominant arteriopathy with subcortical infarcts and leukoencephalopathy (CADASIL) is a hereditary disease due to mutations in the Notch3 gene on chromosome 19p13 [1-3]. Its clinical spectrum includes migraine with or without aura, psychiatric disturbances, stroke and dementia [1, 2, 4]. Other disturbances, including epilepsy, acute reversible encephalopathy and myopathy have also been reported $[5,6]$.

We describe a patient presenting with a novel migrainous presentation of CADASIL.

\section{Case report}

A 34-year-old woman was evaluated in our outpatient clinic for a severe headache associated with visual disturbances. She reported that her father had had a stroke at the age of 40 years. She had had two healthy childbirths, she did not have any vascular risk factors, nor was she taking oral contraceptives. She had migraine without aura and during the previous 4 years she had had three attacks of migraine with typical visual aura that resolved with a single $50 \mathrm{mg}$ dose of oral sumatriptan. Eight days before our first evaluation, she had complained of flashing lights in the left visual field and had had left mouth and left arm paresthesias lasting $20 \mathrm{~min}$, followed by a unilateral, pulsating, severe head pain. A single oral dose of sumatriptan $50 \mathrm{mg}$ was ineffective. She thus took further four pills of sumatriptan $50 \mathrm{mg}$ within the next $6 \mathrm{~h}$. The following day not only did the pain remained unchanged, but she developed a persistent left visual disturbance. She consulted her physician who suggested that she took oral ibuprofen $400 \mathrm{mg}$ and ketorolac $10 \mathrm{mg}$ i.m. as rescue treatment that partially 
relieved her head pain. At the neurological examination, she presented psychomotor slowness, confusion, difficulty in speech, left lateral hemianopia, and paresthesias on the left side of the face and on the left upper limb. Tendon reflexes were ++ on both sides and plantar responses were normal. Blood pressure was 130/80 $\mathrm{mmHg}$.

The patient underwent an urgent brain magnetic resonance imaging (MRI) that showed, on both T2-weighted and fluid-attenuated inversion recovery images, white matter areas with increased signal intensity in the periventricular and subcortical regions and confluent hyperintense signals in the anterior part of the temporal lobes (Fig. 1). T1-weighted and diffusion-weighted sequences were normal. Shortly after the brain MRI, the patient had a generalized tonicclonic seizure. She was treated with lorazepam $2 \mathrm{mg}$ i.v. and mannitol 18\% $500 \mathrm{~mL}$ i.v. by the consulting anesthesiologist and thereafter hospitalized. Following the administration of lorazepam and mannitol, the neurological deficits and the headache gradually resolved within $2 \mathrm{~h}$. Laboratory and cerebrospinal fluid examinations as neck vessels and transcranial duplex scans were normal. A repeat brain MRI with contrast medium performed on the second day of hospitalization confirmed the same findings. MR-angiography of the intracranial vessels was normal. The electroencephalogram (performed $24 \mathrm{~h}$ after the resolution of symptoms) showed waves at 5-7 Hz bilaterally in the fronto-temporal regions. The Notch 3 gene analysis revealed a heterozygous mutation in exon 4 (R141C) while the skin biopsy showed deposits of granular osmiophilic material (GOM) within the vascular smooth muscle basal lamina, which are pathognomonic for CADASIL.

\section{Discussion}

Different types of migraine have been reported in 20-40\% of patients with CADASIL, including migraine with typical

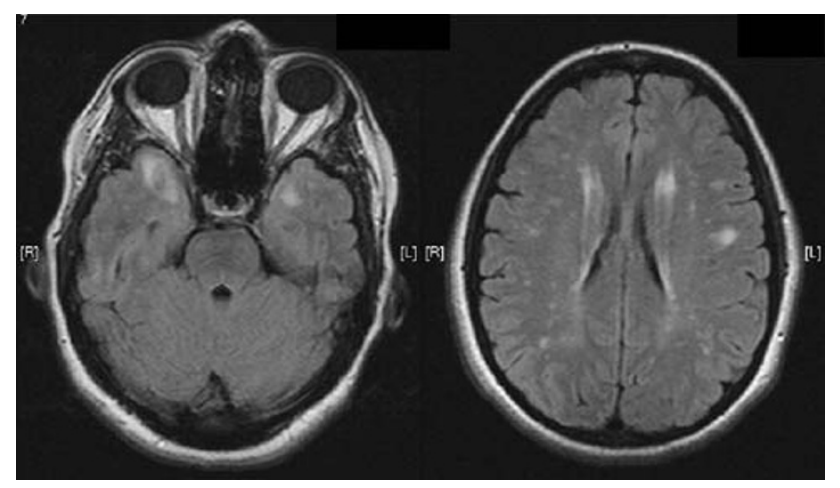

Fig. 1 Brain magnetic resonance imaging showing, on fluid-attenuated inversion recovery sequences, hyperintense lesions in the anterior part of the temporal lobes (right) and in the periventricular and subcortical regions (left) aura, which accounts for the majority of cases, migraine without aura, migraine aura without headache, basilar migraine, hemiplegic migraine, acute onset aura without headache, migraine with acute onset aura, migraine with prolonged aura and retinal migraine $[1,4,6-8]$. Our patient fulfilled the clinical diagnostic criteria for status migrainosus [International Classification of Headache Disorders, Second Edition (ICHD-2) 1.5.2] and persistent aura without infarction (ICHD-2 1.5.3) [9]. Although cases with prolonged aura (lasting more than $1 \mathrm{~h}$ ) have been described in CADASIL, our patient exceptionally suffered both persistent aura (aura symptoms persisting for more than 1 week) and status migrainosus (a debilitating migraine attack lasting for more than $72 \mathrm{~h}$ ). Such symptoms may have been exacerbated or even caused by the repeated intake of sumatriptan. To our knowledge, no previously published studies include data on triptans use in patients with CADASIL despite it is well known that triptans should not be given in patients with cerebrovascular disease. An appealing disease hypothesis in CADASIL is that the damage to vascular smooth muscle cells reduces cerebral perfusion and prevents cerebral vessels from autoregulation [10]. The sumatriptan taken by our patient might have induced an abnormal vasoconstrictor response that generated and maintained the persistent aura.

The second interesting finding is that the patient presented, during the course of the status migrainosus and the persistent aura without infarction, her first epileptic seizure. This association might have occurred by chance or the epileptic seizure might also have been triggered by the migraine (ICHD-2 1.5.5 migraine-triggered seizure) [9]. This hypothesis needs to be tested.

A third interesting point is that the status migrainosus and the persistent aura without infarction resolved after i.v. treatment with lorazepam and mannitol that were given by the referral anesthesiologist. The temporal relationship between treatment and relief of symptoms suggests a cause and effect association, though we cannot establish whether the benefits are attributable to lorazepam, mannitol, or both. The possible therapeutic benefits of the antiepileptic treatment might be inferred from a report of six patients with CADASIL who presented with acute encephalopathy, characterized by fever, confusion, coma, and fits preceded by a prolonged attack of migraine with aura which resolved after i.v. phenytoin [5]. If the benefits are attributable to lorazepam, it might be possible that the patient had suffered from a non-convulsive status epilepticus, as reported in another study [6], rather than status migrainosus and persistent aura without infarction. The fact that the patient performed the electroencephalogram only $24 \mathrm{~h}$ after the symptoms had resolved prevented us from ruling out a nonconvulsive status epilepticus, though we consider it unlikely given the 8-day duration of the symptoms. 
Our last consideration concerns the relationship between what we know about CADASIL and what is currently reported in the ICHD-2 [9]. The headache in CADASIL is commonly reported as migraine because it fits the clinical characteristics of migraine far more closely than that of a generic headache. However, the diagnostic criteria for any type of migraine in the ICHD-2 state that the disturbance must not be attributed to another disorder. Headache attacks in patients with CADASIL do not, thus, fulfill the diagnostic criteria for migraine. Headache in patients with CADASIL is classified, according to the ICHD-2, as Headache attributed to cranial or cervical vascular disorder for the implicit assumption that the vascular disorder is the cause of the headache. However, as previously suggested $[4,11]$, the consideration may be incorrect because headache can be present in patients without ischemia or hemorrhage as in the present case. It may be more correct to attribute the headache to the genetic alteration, which might give rise to the symptoms through a still unknown mechanism. For these reasons, we suggest that a new category might more appropriately be added to the ICHD-2 to classify the migraine attacks of patients with CADASIL. The name for such a category might be Migraine attributed to genetic disorder [11].

Conflict of interest None.

\section{References}

1. Chabriat H, Vahedi K, Iba-Zizen MT, Joutel A, Nibbio A, Nagy TG et al (1995) Clinical spectrum of CADASIL: a study of 7 families. Cerebral autosomal dominant arteriopathy with subcortical infarcts and leukoencephalopathy. Lancet 346:934-939

2. Joutel A, Corpechot C, Ducros A, Vahedi K, Chabriat H, Mouton P, Alamowitch S, Domenga V, Cécillion M, Marechal E, Maciazek J, Vayssiere C, Cruaud C, Cabanis EA, Ruchoux MM, Weissenbach J, Bach JF, Bousser MG, Tournier-Lasserve E (1996) Notch3 mutations in CADASIL, a hereditary adult-onset condition causing stroke and dementia. Nature 383:707-710

3. Sacco S, Olivieri L, Bastianello S, Carolei A (2006) Comorbid neuropathologies in migraine. J Headache Pain 7:222-230

4. Vahedi K, Chabriat H, Levy C, Joutel A, Tournier-Lasserve E, Bousser MG (2004) Migraine with aura and brain magnetic resonance imaging abnormalities in patients with CADASIL. Arch Neurol 61:1237-1240

5. Schon F, Martin RJ, Prevett M, Clough C, Enevoldson TP, Markus HS (2003) "CADASIL coma": an underdiagnosed acute encephalopathy. J Neurol Neurosurg Psychiatry 74:249-252

6. Valko PO, Siccoli MM, Schiller A, Wieser HG, Jung HH (2007) Non-convulsive status epilepticus causing focal neurological deficits in CADASIL. J Neurol Neurosurg Psychiatry 78:1287-1289

7. Desmond D, Moroney J, Lynch T, Chan S, Chin S, Mohr JP (1999) The natural history of CADASIL. Stroke 30:1230-1233

8. Dichgans M, Mayer M, Uttner I, Brüning R, Müller-Höcker J, Rungger G, Ebke M, Klockgether T, Gasser T (1998) The phenotypic spectrum of CADASIL: clinical findings in 102 cases. Ann Neurol 44:731-739

9. Headache Classification Subcommittee of the International Headache Society (2004) The International Headache Classification of Headache Disorders, 2nd edn. Cephalalgia 24(Suppl 1):9-160

10. Chabriat H, Pappata S, Ostergaard L, Clark CA, Pachot-Clouard M, Vahedi K, Jobert A, Le Bihan D, Bousser MG (2000) Cerebral hemodynamics in CADASIL before and after acetazolamide challenge assessed with MRI bolus tracking. Stroke 31:19041912

11. Sacco S, Carolei A (2007) Migraine attributed to genetic disorder. Funct Neurol 22:117-118 